\title{
Correlation between Six Minute Walk Test and Physiological Cost Index in Healthy Indian Females
}

\author{
Harshita Sharma ${ }^{1}$, Aparna Sarkar ${ }^{2}$ \\ ${ }^{1} \mathrm{PhD}$ Scholar, Singhania University, Pacheri Bari, Distt. Jhunjhunu, Rajasthan, India
}

\begin{abstract}
Objective: To analyze the correlation between Physiological Cost Index and the 6 Minute Walk Test Parameters and demographics. Participants: Convenience samples of 24 healthy females, age between 25 to 50 years. Intervention: PCI, was calculatedafter measuring the resting vitals, where subject walked at self-selected speed, wearing an ambulatory heart rate meter. For six minute walk test, the subject was asked to walk for six minutes so as to cover maximal distance possible, which was measured, along with posttest vitals to arrive at values of distance covered, VO2max, change in HR, and SBP. Result: Mean age was 33.9 \pm 8.248 years. Mean height of the subjects was $155.2 \pm 5.414 \mathrm{~cm}$. Mean weight was $58.3 \pm 12.855 \mathrm{~kg}$, mean BMI was $23.86 \pm 4.996 \mathrm{~kg} / \mathrm{m}^{2}, \mathrm{mean} 6 \mathrm{MWD}$ was $444.4 \pm 53.05$ meters, mean VO2 max was $35.53 \pm 3.225 \mathrm{ml} \mathrm{kg}^{-1} . \mathrm{min}^{-1}$, mean rise in heart rate was $35.7 \pm 18.1$ beats per minute, mean rise in SBP was $10.83 \pm 3.985 \mathrm{~mm}$ of $\mathrm{Hg}$, and mean PCI was 0.42564 beats per meter.A Pearson correlation between the studied variables and PCI was found to be moderately positively correlated with weight, height, BMI, 6MWD, increase in heart rate post exercise. There was a mild negative correlation between PCI and age, as well as change in SBP. However, VO2 max did not correlate with PCI values. Conclusion: Physiological cost of walking in normal Indian females is directlyassociated with the weight, BMI, 6MWD, increase in heart rate post exercise of the individual. However, the inverse relation between SBP and PCI, and no correlation with VO2 max needs to be investigated further.
\end{abstract}

Keywords: Physiological Cost Index, 6 Minute Walk Test, 6 Minute Walk Distance, BMI, VO2

\section{Introduction}

Health and fitness is an important factor that contributes to human wellbeing. Currently, women in India face numerous health issues, which ultimately affect the aggregate economy's output.Indian women have high mortality rates, particularly during childhood and in their reproductive years. The health of Indian women is intrinsically linked to their status in society. Multiple factors exert a negative impact on the health status of Indian women. Poor health has repercussions not only for women but also their families. Women in poor health are more likely to give birth to lowweight infants. Research has shown that numerous pregnancies and closely spaced births erode a mother's nutritional status, which can negatively affect the pregnancy outcome (e.g., premature births, low birth-weight babies) and also increase the health risk for mothers [1]. In fact,India has a high maternal mortality ratio-approximately 453 deaths per 100,000 births in 1993. Moreover, the negative effects of malnutrition among women are compounded by heavy work demands, by poverty, by childbearing and rearing, and by special nutritional needs of women, resulting in increased susceptibility to illness and consequent higher mortality [2]. Given such a grim picture, it is imperative to analyze the health and fitness levels of women in India, and draw out normative figures regarding the basic markers of fitness and endurance, which one can then apply to the population in question. Some of the basic measures of fitness and energy expenditure include BMI, PCI, VO2 max, and 6MWD.Increase in BMI is related with a lot of chronic diseases [3]-[6].

\section{Literature Survey}

The traditional parameter of measuring energy expenditure has been the oxygen uptake[7]-[8]. Authors developed the Physiological Cost Index(PCI) for measuring the energy expenditure of walking [9]. It is easy to apply in clinics, no heavy equipment required,and influence of emotional stress, fitness,medication, illness and ambient temperature are very small.For these advantages, there have been many studies using the PCI to measure energy expenditure of ambulation in normal children and children with ambulation disabilities [10]-[18].The PCI enables the therapist to carry out energy cost assessment in the clinical setting. The heart rate is the simplest and the most direct measure of physical effort.For normal people and people with lower extremity handicaps, heart rate has been shown to be areliable monitor of energy expenditure because it is linearly related to the rate of oxygen uptake under submaximal workloads. Therefore, heart rate has been recommended as a method of measuring energy cost[19]-[20].

The Physiological Cost Index (PCI) proposed by MacGregor [9] is calculated as the quotient of the difference in working and resting heart rates and walking speed. The PCI value reflects the increased heart rate required for walking and is expressed as heartbeats per meter. PCI may provide a measure of overall walking performance, inasmuch as it includes both a physiologic measurement and velocity. The correlation between PCI and VO2 has been studied in healthy adults[10]. The retest reliability of PCI has been investigated in healthy subjects[10]-[13]children with cerebral palsy [15] and adults with spinal cord [13] and brain injuries[16].PCI has been used as an outcome measure after interventions in persons with cerebral palsy [17],spinal cord injury [18], [19] and stroke[21], [22].

The Six-Minute Walk Test (6 MWT) is an inexpensive, relatively quick, safe and a well-tolerated method ofassessing the functional exercise capacity of patients withmoderate-tosevere heart or lung disease. Its use hasfound popularity in following the natural history of variousdiseases, for timing of procedures such as heart orlung transplantation and for measuring the response tomedical interventions[24]. The 6-

\section{Volume 5 Issue 2, February 2016}




\section{International Journal of Science and Research (IJSR) \\ ISSN (Online): 2319-7064 \\ Index Copernicus Value (2013): 6.14 | Impact Factor (2014): 5.611}

minute walk test (6MWT) is a widely used field-based assessment that evolvedfrom the original Cooper 12-minute run/walk test and the 12-minute walk test for bronchitis [25].The 6MWT was originally developed to evaluate the functional capacity, monitor the effectiveness of several treatments and establish the prognosis of patients with cardio respiratory diseases[24]. The main aim of this study was to investigate the correlation of PCI with the Six Minute Walk Test parameters in healthyIndian females.

\section{Methods/ Approach}

Twenty four healthy normal femalesvolunteers aged between 25 to 50 years were selected. None of the participants had been engaged in any exercise training. Also, none of them had a history of respiratory or cardiac diseases, any airway disorder, or thoracic, abdominal, ENT or ophthalmic surgery. None of them had any sign or symptom of medical instability including postpartum problems like perineal pain, backache, diastasis recti, mastitis, breast abscess, stress incontinence, or diastasis symphysispubis.

\subsection{Subject Preparation}

The subject's usualmedical regimen, if any, was to be continued.A light meal was acceptablebefore early morning or early afternoon tests. Subjects wouldnot have exercised vigorously within 2 hoursof beginning thetest. The subject was then instructed /helped to fill the questionnaire regarding herself.All the participants received a full explanation of the study's purposes and a consent form was read and signed by the subjects before the study. Information regarding the subjects demographic data, age, height, weight, medical and obstetric history and current medical status was obtained from subjects.

\subsection{Equipment Required}

Acouch, sphygmomanometer, weighing machine, a stop watch, work sheets, POLAR ${ }^{\circledR}$ Heart Rate monitor consisting of a chest band, and a wrist monitor to measure the immediate accurate heart rate, alcohol swabs, a 25 meter walking pathway, two small cones to mark the turnaround points, and a chair to be kept along the walking course.

\subsection{Measurements}

\subsubsection{Physiological Cost Index}

An ambulatory pulse rate meter wasplaced on the chest of the subject, and she was made to rest comfortably to first obtain the resting heart rate.Two such readings were taken in an interval of ten minutes and the lower one was selected. The subject was instructed to walk to and fro the walkway at a comfortable walking speed that one normally uses to walk. Heart rate and time was recorded at the end of each excursion of 25 meters, repeated eight times. Average walking heart and Physiological Cost Index was calculated as following:

$\mathrm{PCI}=\{\mathrm{HR}(\mathrm{w})-\mathrm{HR}(\mathrm{r})\}$ xtotal time walked/ total distance walked

Where: $\mathrm{HR}(\mathrm{w})=$ Average Walking Heart Rate; $\mathrm{HR}(\mathrm{r})=$ Resting Heart rate

\subsubsection{Six Minute Walk Test}

The subject was made torest in a chair, located near thestarting position, for atleast 10 minutes before the beginning of the test.During this time, the patient was checkedfor any contraindications, making sure that clothing and footwear wereappropriate. The resting heart rate and blood pressure was measured before beginning the test. The subject was instructed to try and cover as much distance as possible by walking to and fro along the 25 meter walkway till six minutes, whichwas counted by a stopwatch. A chair was placed along the walkway so that the subject could sit and restwhenever she felt dizzy/uneasy/unable to walk and could restart as possible. At the end of six minutes, the subject was made to lie on the couch and the immediate heart rate was measured and recorded, along with the distance covered in six minutes.

\subsubsection{Estimated VO2 max}

Estimated VO2 $\max (\mathrm{mL} \cdot \mathrm{kg}-1 \cdot \mathrm{min}-1)=70.161+(0.023 \times$ $6 \mathrm{MWT}[\mathrm{m}])-(0.276 \times$ weight $[\mathrm{kg}])-(6.79 \times$ sex, where $\mathrm{m}=$ $0, \mathrm{f}=1)-(0.193 \times$ resting HR [beats per minute] $)-(0.191 \times$ age $[y]$ ) was calculated according to the formula [26].

\section{Statistical Analysis /Results}

The independent variables such as age, height, weight, BMI, distance covered, change in Heart Rate, VO2 max, change in Systolic Blood Pressure and dependent variable PCIwas first expressed as mean \pm standard deviation and variance was also calculated.Pearson correlation coefficient was calculated between the above parameters and PCI values respectively.

Mean age was $33.9 \pm 8.248$ years. Mean height of the subjects was $155.2 \pm 5.414 \mathrm{~cm}$. Mean weight was $58.3 \pm 12.855 \mathrm{~kg}$, mean BMI was $23.86 \pm 4.996 \mathrm{~kg} / \mathrm{m}^{2}$, mean 6 MWD was 444.4 \pm 53.05 meters, mean VO2 max, as calculated using 6MWT recorded parameters was $35.53 \pm 3.225 \mathrm{ml} . \mathrm{kg}^{-1} \cdot \mathrm{min}^{-1}$, mean rise in heart rate was $35.7 \pm 18.1$ beats per minute, mean rise in SBP was $10.83 \pm 3.985 \mathrm{~mm}$ of $\mathrm{Hg}$, and mean PCI was 0.4435 beats per meter.

Table1: Demographic data of the subjects.

\begin{tabular}{|c|c|c|c|c|}
\hline $\mathrm{N}=24$ & $\begin{array}{c}\text { Age } \\
\text { in years }\end{array}$ & $\begin{array}{c}\text { Height } \\
\text { in cm }\end{array}$ & $\begin{array}{c}\text { Weight } \\
\text { in } \mathrm{kg}\end{array}$ & $\begin{array}{c}\mathrm{BMI} \\
\text { inkg/m }\end{array}$ \\
\hline Mean & 33.9 & 155.2 & 58.33 & 23.86 \\
\hline Standard deviation & 8.248 & 5.404 & 12.855 & 4.9964 \\
\hline Variance & 68.04 & 29.19 & 165.25 & 24.964 \\
\hline $\begin{array}{c}\text { Pearson } \\
\text { Correlation Coefficient }\end{array}$ & -0.23 & -0.47 & 0.386 & 0.473 \\
\hline
\end{tabular}

Table 2: Correlation of PCI with 6MWD, VO2 max, Rise in HR, SBP Rise Post 6MWT

\begin{tabular}{|c|c|c|c|c|}
\hline $\mathrm{N}=24$ & $\begin{array}{c}\text { 6MWD } \\
\text { in meters }\end{array}$ & $\begin{array}{c}\mathrm{VO}_{\mathrm{ml}} \mathrm{max}^{-1} \cdot \mathrm{min}^{-1} \\
\text { Mean }\end{array}$ & $\begin{array}{c}\text { Rise HR in } \\
\text { beats per } \\
\text { minute }\end{array}$ & $\begin{array}{c}\text { SBP Rise } \\
\text { post 6MWT } \\
\text { in mm of Hg }\end{array}$ \\
\hline $\begin{array}{c}\text { Standard } \\
\text { deviation }\end{array}$ & 53.036 & 35.53 & 35.71 & 10.83 \\
\hline Variance & 2812.824 & 10.385 & 291.781 & 14.928 \\
\hline $\begin{array}{c}\text { Pearson } \\
\text { Correlation } \\
\text { Coefficient }\end{array}$ & 0.408 & -0.0428 & 0.455 & -0.292 \\
\hline
\end{tabular}

Correlation H.R.: Heart Rate

B.P.: Systolic Blood Pressure 


\section{International Journal of Science and Research (IJSR) \\ ISSN (Online): 2319-7064}

Index Copernicus Value (2013): 6.14 | Impact Factor (2014): 5.611

\subsection{Figures}

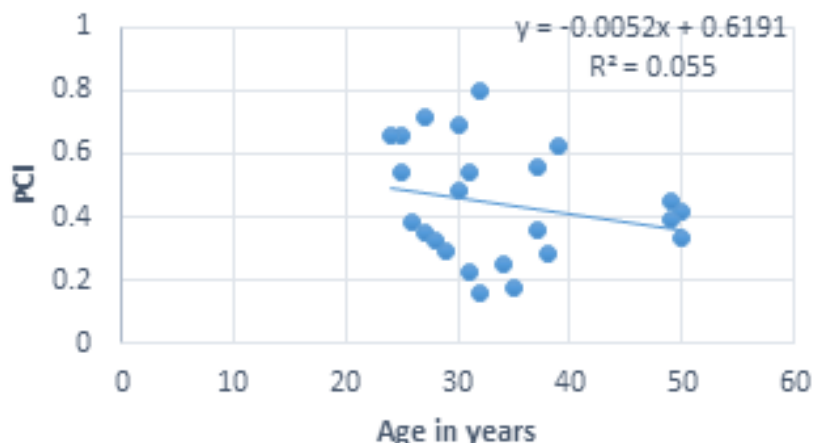

Figure 1: Correlation of Age( $\mathrm{x} 1)$ with Physiological cost Index

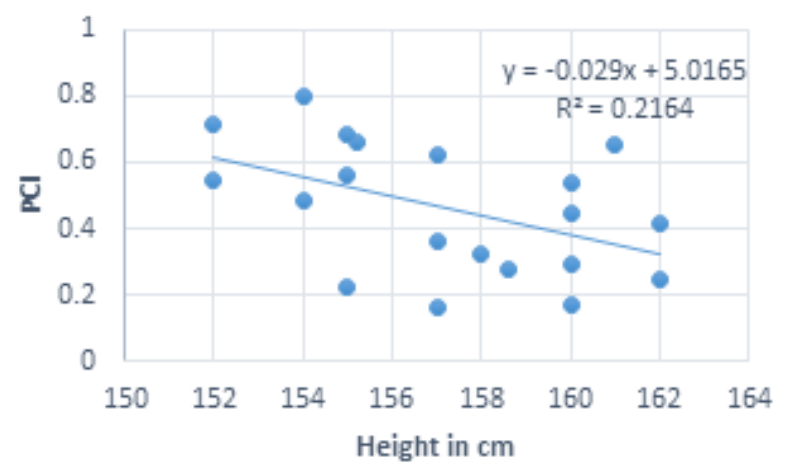

Figure 2: Correlation of Height (x2) with Physiological cost Index

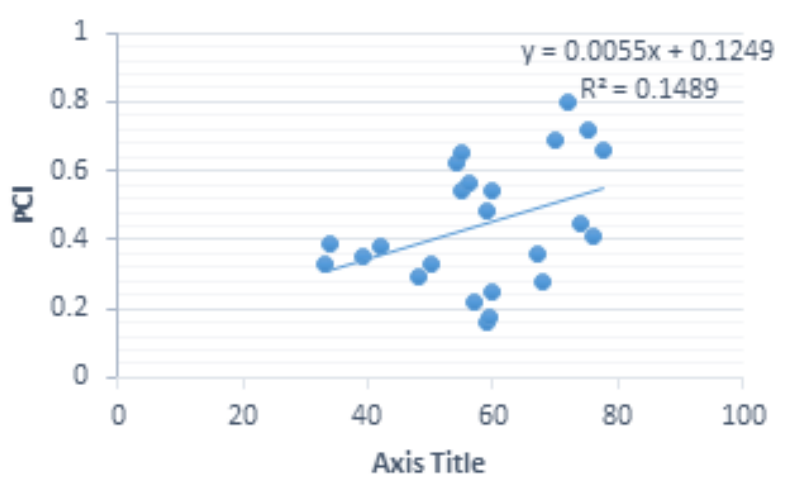

Figure 3: Correlation of Weight (x3) with Physiological cost Index

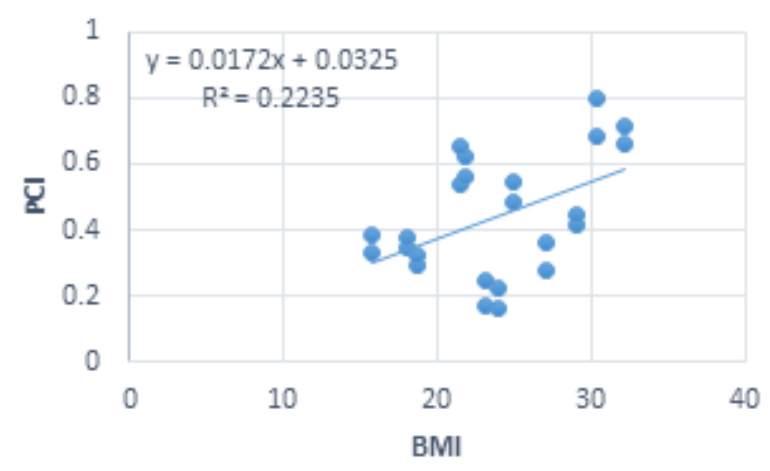

Figure 4: Correlation of Body Mass Index (BMI) (x4) with Physiological cost Index

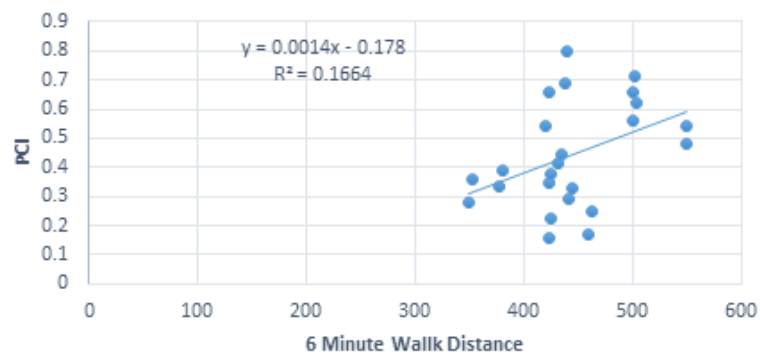

Figure 5: Correlation of Six Minute Walk Distance (x5) with Physiological cost Index

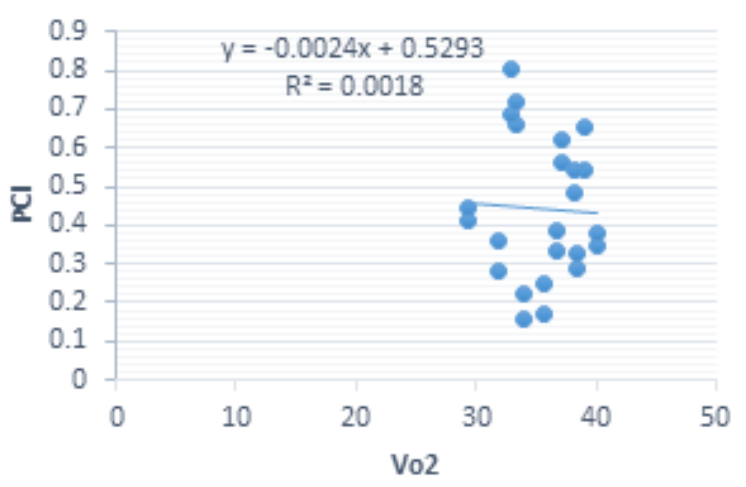

Figure 6: Correlation ofVO2 Max (x6) with Physiological cost Index

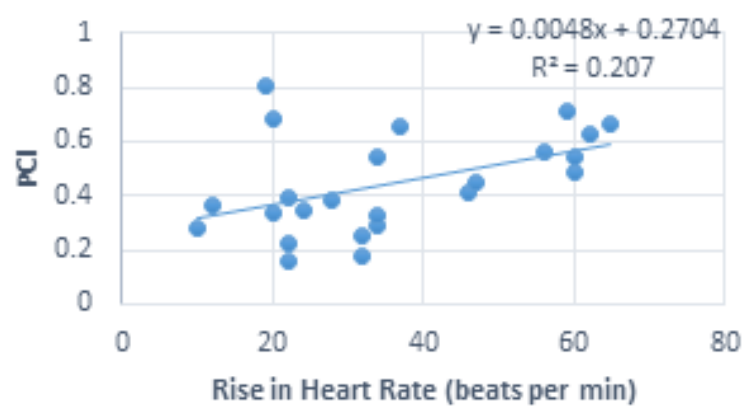

Figure 7: Correlation of Heart Rate (x7) with Physiological cost Index

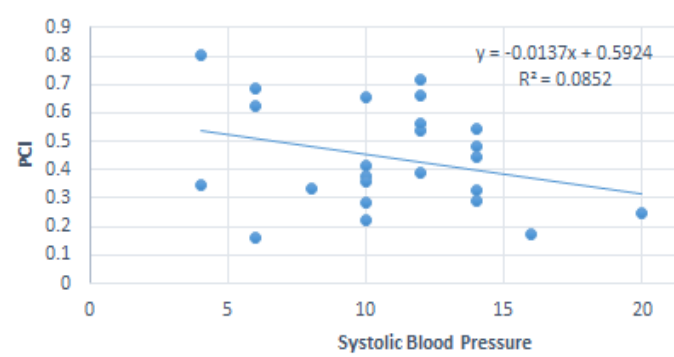

Figure 8: Correlation of Systolic Blood pressure (x8) with Physiological cost Index

When Pearson Product Moment Correlation was applied to ascertain the correlation between the dependent variable PCI with the independent variables such as age, height, weight, BMI, 6MWD, VO2, change in HR and SBP from rest values after the 6MWD; the following observations came up:

The Physiological Cost Index was shown to have mild negative correlation with increasing age in normal healthy Indian women(r value $=-0.23$ ). Initially, height did not seem to have much of a correlation with PCI in the studied sample, 


\section{International Journal of Science and Research (IJSR) \\ ISSN (Online): 2319-7064 \\ Index Copernicus Value (2013): 6.14 | Impact Factor (2014): 5.611}

but after removing four outlier points of least height, the correlation became significant $(\mathrm{r}$ value $=-0.47)$. In the given sample of non obese and non overweight Indian females, weight and BMI seemed to be positively correlated with the PCI, (r value0.386 and 0.473 respectively).

In this study, VO2 max calculated during the 6MWT did not correlate with PCI of the individual ( $\mathrm{r}$ value $=-0.0428$ ). The distance walked in six minutes (6MWD) showed a moderate positive correlation with the $\mathrm{PCI}(\mathrm{r}$ value $=0.408)$

The increase in heart rate post exercise was also positively correlated with the increase in PCI ( $\mathrm{r}$ value $=$ 0.455). However, change in SBP with 6MWT showed a mild negative correlation with PCI ( $\mathrm{r}$ value $=-0.292$ ) as shown in Table2.

\section{Discussion}

The mean 6MWD of443.04 \pm 53.036 meters, and mean VO2 max, as calculated using 6MWT recorded parameters was $35.53 \pm 3.226$, which compares well with the study by Sahin et al, 2013 [27], where the 6MWT distance of the middleaged women aged $37.45 \pm 8.7$ years living in Canakkale, Turkey was found $419.77 \pm 72.31$, the estimated VO2 max was $32.25 \pm 4.62 \mathrm{~mL} \cdot \mathrm{kg}-1 \cdot \mathrm{min}-1$.

The Physiological cost Index was shown to have mild negative correlation with increasing age in normal healthy Indian women. Initially, height did not seem to have much of a correlation with PCI in the studied sample. This finding is in line with Mac Donald 1961[28], whoreviewed literatures from 1912 to 1958 . He found no significant correlation between age or height and the energy expenditure of walking. However, after removing outliers subjects from the graph the height showed a mild positive correlation with PCI. This association therefore needs further exploration. As per Mac Donald [28],walking speed, sex, and weight significantly influenced the energy expenditure of walking.

In the given sample of non obese and non overweight Indian females, weight and BMI seemed to be positively correlated with the PCI, thereby indicating that with increase in body weight, the physiological cost of walking tends to increase as well. There were conflicts regarding the effect of sex, weight and leg length on the energy expenditure [14], [11], [29].In a study involving fifty people of variation in only weight(48$110 \mathrm{~kg})$, age (13-79 yrs), sex, height (150-188 cm) and race European and Asiatic, Kamadeva et al[29]measured the Oxygen uptakeduring stepping and walking. Stepping was carried out on a 10 inch stool at a rate of 15 steps per minute for ten minutes. Walking took place on an indoor track the subjects walked for ten minutes at $80 \mathrm{~m} / \mathrm{min}(3 \mathrm{mph})$. They found that in stepping, the energy expenditure was directly proportional to body weight; in walking, the regression line was also linear but did not pass through the origin. Statistical analysis showed that no significant difference in PCI was obtained by taking into account the height, sex, age and race for the individual. The authors concluded that in any physical activity, a large proportion of the energy was used to move the body weight and the metabolic cost was directly proportional to the body weight.
The 6MWD, or the distance walked in six minutes showed a moderate positive correlation with the PCI. This seems empirical, since the physiological cost should increase according to the increase in distance travelled. The same logic extends to the increase in heart rate post 6MWT, and therefore the increase in heart rate post exercise was also positively correlated with the increase in PCI. This linear positive correlation is more so probably because the PCI is calculated based on the resting and average heart rate during the eight 25 meter excursions.

However, change in SBP with 6MWT showed a mild negative correlation with PCI. This finding seems to be a little unusual. In the recent international researches, it isascertained that healthy African-American and EuropeanAmerican women in similar age groups have more fat percentage and BMI values, according to Hunter et al, 2010 ,[30], and less oxygen capacity than Turkish women; as another survey which has revealed the ethnic differences between Latin and black women in similar age group, those black andLatin women have higher BMI than the Turkish women as per Sa'nchez-Johnsen et al, 2012 [31].When compared with middle-aged Spanish and Moroccan women, the walking distanceof the Turkish women in their research was less than those Spanish and Moroccan women. The flexibility of lower extremity of the Turkish women was also less than the women in these countries; but the Turkish women were betterin terms of fat percentage, BMI and lower extremity strength as per Aparicio et al,2012[32].Compared with African womenin same age group, BMI and oxygen consumption capacity of the African women were determined to fare better than Turkish women according to Christensen et al,2012 [33]. Furthermore,the BMI of the Japanese women was found to be less, but VO2 max was higher than the Turkishwomen as per Cao et al, 2010[34].

\section{Conclusion}

Physiological cost of walking in normal Indian females is directlyassociated with the weight, BMI, $6 \mathrm{MWD}$, increase in heart rate post exercise of the individual. However, the inverse relation between SBP and PCI, and no correlation with VO2 max needs to be investigated further and could be explained due to extraneous factors.

\section{Future Scope}

This study opens doors to further exploration on the studied parameters, and suggests inclusion of these parameters in assessment protocols of women health, to give a better picture of functional status, as opposed to the clinical status which is stressed upon in current health scenario.

\section{References}

[1] Jejeebhoy, J. Shireen, R.R. Saumya, Unsafe Motherhood: A Review of Reproductive Health," in Monica Das Gupta, Lincoln C. Chen and T.N. Krishnan, eds., Women's Health in India: Risk and Vulnerability, Bombay, 1995.

[2] Women health in India",U.S. Department of Commerce Economics and Statistics Administration BUREAU OF 


\section{International Journal of Science and Research (IJSR) ISSN (Online): 2319-7064 \\ Index Copernicus Value (2013): 6.14 | Impact Factor (2014): 5.611}

THE

CENSUS, 1998,

https://www.census.gov/population/international/files/wi d-9803.pdf

[3] PD. Reaven, E. Barrett-Connor,S. Edelstein, (1991). Relation between leisure-time physical activity and blood pressure in older women,"Circulation, 83(2),pp $559-565,1991$

[4] G.F. Fletcher, S.N. Blair, J. Blumenthal, C. Caspersen, B. Chaitman, S. Epstein, H. Falls, E.S. Froelicher,V.F. Froelicher, I.L. Pina, -Statement on exercise: benefits and recommendations for physical activity programs for all Americans. A statement for health professionals by the Committee on Exercise and Cardiac Rehabilitation of the Council on Clinical Cardiology, American Heart Association." Circulation. 86(1),pp340-344, 1992.

[5] A. Heinonen, P. Oja, H Sievanen, M. Pasanen,I. Vuori, Effect of two training regimens on bone mineral density in healthy perimenopausal women: a randomized controlled trial," J Bone Miner Res., 13(3), pp 483-490,1998.

[6] R Hatemi, V.D. Yumuk, N. Turan,N Arik,-Prevalence of Overweight and Obesity in Turkey"1(4):285- 290, 2003

[7] R. Blessey, H. Hislop, R.L. Waters, D. Antonelli, Metabolic energy cost of unstrained walking," Therapy, 569, pp1019-1024, 1976.

[8] J. Booyens, W.R. Keatinge,-The expenditure of energy by men and women walking," Journal of Physiology, 138, pp165-171, 1957.

[9] J. MacGregor, The evaluation of patient performance using long-term ambulatory monitoring technique in the domiciliary environment," Physiotherapy, 67(2), pp 3033, 1981

[10] T. Chin, S. Sawamura, H. Fujita, S Nakajima,I Ojima, H. Oyabu, Y. Nagakura, H. Otsuka,\&A. Nakagawa, The efficacy of physiological cost index (PCI) measurement of a subject walking with an intelligent Prosthesis," Prosthetic and Orthotics International, 23, pp 45-49, 1999.

[11] R.T. Loder, \&J.A. Herring, Đisarticulation of the knee in children" The Journal of Bone and Joint Surgery, 69(A), pp1155-116,1987.

[12] K.A Mossberg, K.A. Linton, \& K. Firske,-Ankle foot orthoses: effect on energy expenditure of gait in spastic diplegic children," Archives of Physical Medicine and Rehabilitation, 71, pp 490-494, 1990.

[13] G. Mukherjee,\& A. Samanta, Evaluation of ambulatory performance of the arm propelled three-wheeled chair using heart rate as a control index," Disability and Rehabilitation, 22, pp 464-470, 2000.

[14] G. Mukherjee,\& A. Samanta, Physiological response to the ambulatory performance of hand-rim and arm-crank propulsion system," Journal of Rehabilitation Research and Development, 38, pp 391-399, 2001.

[15]G. Mukherjee,\& A. Samanta, Arm-crank propelled three-wheeled chair: physiological evaluation of the propulsion using one arm and both arm patterns"International journal of rehabilitation research, 27(4), pp 321-324, 2004.

[16] D. Popovi, M.Radulovi,L. Schwirtlich, \& N. Jaukovi,-Automatic vs hand controlled walking of paraplegics," Medical engineering \& physics, 25(1), pp 63-73, 2003.
[17] J. Rose, J. G Gamble, A. Burgos, J. Medeiros, W. L. Haskel, Energy expenditure index of walking for normal children and for children with cerebral palsy,'Developmental Medicine and Child Neurology, 32, pp 333-340, 1990.

[18] T. Suzuki, S. Sonoda, S. E. Saitoh,M. Murata, A. Uno, Y. Shimizu, K. Misawa, T. Kotake, Đevelopment of a novel type of shoe to improve the efficiency of kneeankle foot orthoses with a medial single hip joint (Primewalk orthoses): a novel type of shoe for Primewalk orthosis," Prosthetics and orthotics international, 29(3), pp 303-311, 2005.

[19]R.C. Graham, N.M. Smith, M. Claire, The reliability and validity of the physiological cost index in healthy subjects while walking on 2 different tracks," Archives of physical medicine and rehabilitation, 86(10), pp 2041-2046, 2005

[20]C. MacArthur M. Lewis, E.G .Knox, Health AfterChildbirth,'Brit .J. Obstet. Gynaec., 98, pp 1193-5, 1991.

[21] S.V. Fisher, G Gullickson, Energy cost of ambulation in health and disability: a literature review," Archives of Physical Medicine and Rehabilitation, 59, pp 124-133, 1978.

[22]P. Butler, M. Engelbrecht, R.E. Major, J.H. Tait,S. Stallard, J.H. Patrick, Physiological cost index of walking for normal children and its use as an indicator of physical handicap", Developmental Medicine and Child Neurology, 26, pp 607-612, 1984.

[23] J. Rose, J. G. Gamble, J. Lee, R. Lee, W.L. Haskell, The energy expenditure index: a method to quantitate and compare walking energy expenditure for children and adolescents," Journal of Pediatric Orthopaedics, 11, pp 571-578, 1991.

[24]ATS statement, Guidelines for the six-minute walk test,"Am J RespirCrit Care Med,166(1), pp 111-7, 2002.http://www.atsjournals.org/doi/pdf/10.1164/ajrccm 166.1.at1102

[25] C.R. McGavin,S.P. Gupta,G.J. McHardy, Twelveminute walking test for assessing disability in chronic bronchitis,"Br MedJ, 1(6013), pp 822-823, 1976.

[26] J.F. Burr, S.S. Bredin, M.D. Factor, D.E. Warburton, The 6-minute walk test as a predictor of objectively measured aerobic fitness in healthy working-aged adults," Phys Sports Med., 39 (2), pp 133-9, 2011.

[27]G. Sahin, T. Sogutcu, M.K. Exercise Frequency and Physical Fitness in Women,"American International Journal of Contemporary Research,3 (12) 2013, pp129134,2013

[28] I. MacDonald, Statistical studies of recorded energy expenditure of man. Part II: Expenditure on walking related to weight,sex age, height, speed and gradient," Nutrition Abstract and Review, 32(3), pp739-761, 1961.

[29] K. Mahadeva, R. Passmore, B. Woolf, Individual variations in the metabolic cost of standardized exercises: the effects of food, age, sex and race," Journal of Physiology, 121, pp 225-231, 1953.

[30] G.R. Hunter, P.C. Chandler-Laney, D.W. Brock, C. Lara-Castro, J.R. Fernandez, B.A. Gower, Fat Distribution, Aerobic Fitness, Blood Lipids and Insulin Sensitivity in African-American and EuropeanAmericanWomen," Obesity, 18(2) pp 274-281, 2010. 


\section{International Journal of Science and Research (IJSR) \\ ISSN (Online): 2319-7064}

Index Copernicus Value (2013): 6.14 | Impact Factor (2014): 5.611

[31]L.A.P. Sa'nchez-Johnsen, M.L. Fitzgibbon, Z. Martinovich, M.R. Stolley, A.R. Dyer, V.L. Horn, Ethnic Differences in Correlates of Obesity between Latin-American and Black Women," Obesity Research, 12 (4), pp652-660, 2012.

[32] V.A. Aparicio, F.B. Ortega, A. Carbonell-Baeza, M. Delgado-Fernandez, P. Aranda, Fitness, fatness and cardiovascular profile in South Spanish and.North Moroccon Women,'Nutr Hosp., 27(1), pp227-231, 2012

[33]D.L.Christensen, D. Faurholt-Jepsen, M.K. Boit, Mwaniki, B. Kilonzo, I. Tetens, F.K. Kiplamai, S.C. Cheruiyot, H. Friis, K. Borch-Johnsen, N.J. Wareham, S. Brage, -Cardiorespiratory fitnessand physical activity in Luo, Kamba and Maasai of rural Kenya," American Journal of Human Biology, 24(6), pp 723-729, 2012.

[34]Z.B.Cao, N. Miyatake, M. Higuchi, M. Miyachi, K. Ishikawa-Takata, I. Tabata, Predicting VO2 max with an objectively measured physical activity in Japanase women," Med Sci Sports Exerc., 42 (1),pp179-86, 2010.

\section{Author Profile}

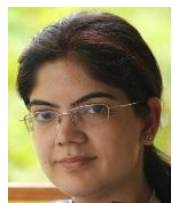

Harshita Sharma received her Bachelor of Physiotherapy and Master of Physiotherapy degree in 2001 and 2004 respectively, in India.She has been engaged in teaching, practicing physiotherapy and creative writing ever since. She is currently pursuing Ph.D. in Physiotherapy from Singhania University, Rajasthan, India. 